\author{
Carlos Agudelo ${ }^{1}$ \\ Université Paris VII-Université Nice Sophia Antipolis \\ agudelo04@yahoo.fr
}

\title{
Movilidades y resistencias de los caribes negros. Pasado y presente de los garífuna ${ }^{2}$
}

\section{Mobilitiy and Resistance of the Black Caribs: The Past and Present of the Garifuna}

\section{Mobilidade e resistência do negro caribe. Passado e presente dos garifunas}

Artículo de reflexión: recibido 14/01/13 y aprobado 08/10/13

I Versión original en francés: "Les Garifuna. Transnationalité territoriale, construction d'identités et action politique”, in REMI, Revue Européenne des Migrations Internationales, 27 (1), 47-70. Una versión previa de este trabajo apareció publicada en Desigualdade \& Diversidade - Revista de Ciências Sociais da PUC-Rio, nº 8, jan/jul, 2011, pp. 51-76. Algunos de los datos de estas primeras versiones han sido actualizados para efectos de la presente publicación.

2 Este trabajo le debe mucho a colegas que vienen trabajando sobre el pueblo garifuna desde mucho antes que yo lo hiciera. La lectura de algunos de sus resultados de investigación como las oportunidades de compartir espacios de reflexión, e incluso conversaciones informales, han sido determinantes para la elaboración de este texto. Un agradecimiento para Alfonso Arrivillaga, Jorge Amaya, Joseph Palacio, Mark Anderson, Darío Euraque y Nicolás Rey; igualmente para Odile Hoffmann por los comentarios y sugerencias a este texto. Un reconocimiento especial para las comunidades y los líderes garifunas que me han acogido y permitido inmiscuirme en su devenir. 



\title{
Resumen
}

Los Caribes negros o Garífunas pueblan desde finales del siglo XVIII las costas caribes de 4 países de América central (Belice, Guatemala, Honduras y Nicaragua). Actualmente, a través de un proceso migratorio constante iniciado a mediados del siglo $\mathrm{XX}$, buena parte de su población habita los Estados Unidos. La transnacionalidad originaria de su territorialización en Centroamérica y su presencia más reciente en Estados Unidos ha estado acompañada siempre de una rica circulación de símbolos identitarios. Estos símbolos articulan diversas representaciones etno-raciales que se transforman bajo la incidencia de procesos políticos y sociales de orden nacional, regional y global, hasta llegar a una identificación genérica como pueblo afrodescendiente. El propósito de este artículo es el de presentar, partiendo de una perspectiva histórica, la dinámica de construcción de las identidades garífunas, los actores que intervienen en dichos procesos y su dinámica política.

Palabras claves: Garífunas, identidades, transnacionalidad, movilización, política.

\begin{abstract}
The black Caribs, or Garifuna, have populated the Caribbean coasts of four Central American countries (Belize, Guatemala, Honduras and Nicaragua) since the end of the eighteenth century. Through a continual process of migration begun in the mid-twentieth century, much of its population currently lives in the United States. The transnationality of the original establishment of their community in Central America and that of their more recent presence in the U.S. have always been accompanied by a rich flow of identity symbols. These symbols articulate diverse ethno-racial representations that have transformed due to the impact of national, global and regional political and social processes to the point of becoming generically identified as a part of the larger Afro-descendent community. This article aims to present, from a historical perspective, the dynamics of the construction of Garifuna identities, the actors involved in these processes and their political dynamics.
\end{abstract}

Key words: Garifunas, Identities, Transnationality, Mobilization, Politics.

\section{Resumo}

Os Garífunas ou caribes negros ocupam, desde o final do século XVIII, as costas caribenhas de quatro países da América Central (Belize, Guatemala, Honduras e Nicarágua). Presentemente, grande parte da população mora nos Estados Unidos, mercê a um processo de migração constante que começou a meados do século XX. O caráter transnacional, próprio da origem territorial na América Central e de sua presença mais recente nos EUA, foi sempre 
acompanhado de um valioso tráfego de símbolos de identificação que articulam várias representações étnico-raciais. Essas representações vão se transformando pela ocorrência de processos políticos e sociais da ordem nacional, regional e global, até adquirir uma identificação genérica como povo afrodescendente. Desde uma perspectiva histórica, o presente artigo tem o intuito de descrever a dinâmica da construção das identidades garífunas, os atores envolvidos nestes processos bem como as dinâmicas políticas.

Palavras-chave: Garifunas, identidade, transnacionalismo, mobilização, política. 
Los garífuna, conocidos inicialmente hasta bien entrado el siglo XX como caribes negros, ${ }^{1}$ son la expresión de un proceso de mestizaje entre africanos procedentes de la trata esclavista e indígenas caribes arawaks, el cual se produce durante el periodo colonial en las Antillas menores, principalmente en la Isla de San Vicente. Deportados masivamente por los ingleses hacia América Central, en 1797 los garífuna comienzan el poblamiento de las costas caribes de Honduras, Belice, Guatemala, y Nicaragua. Actualmente, buena parte de su población habita los Estados Unidos a causa de un proceso migratorio constante iniciado a mediados del siglo XX,

Las estadísticas demográficas sobre la población garífuna en América Central y los Estados Unidos presentan oscilaciones importantes. Según el Informe de Desarrollo Humano de las Naciones Unidas para América Central del año 2003, en Honduras habría 200.000 garífunas, en Belice 15.000, en Guatemala 5.000 y en Nicaragua 2.000, para un total aproximado de unas 222.000 personas. No existen estadísticas precisas sobre las cifras de la población garífuna residente en los Estados Unidos, pero diferentes fuentes ${ }^{2}$ hablan de una cantidad igual o superior a la de los garífuna que habitan Centroamérica. Esto nos daría una población total de unos 400.000 individuos. $^{3}$

El trasegar garífuna ha estado acompañado siempre de una rica, compleja, y a veces contradictoria circulación de símbolos etno-raciales. Estos están presentes desde la llegada forzada de sus ancestros africanos a las islas del Caribe, su proceso de mestizaje Afro indígena y el poblamiento en las Antillas menores. La dinámica construcción identitaria continúa manifestándose en su tránsito hacia Centroamérica como caribes negros en la transnacionalidad

1 En este texto utilizo indistintamente los términos garífuna y caribes negros. Sin embargo, hay que tener en cuenta que hasta mediados del siglo XX, era con la palabra "caribes negros" con la fueron nombrados y también así se auto-representaban cuando hablaban español, el inglés o el francés. En su propia lengua siempre se nombraban como "garífuna" o "garinagu" en plural.

2 Se puede llegar a estas estimaciones gracias Mohr de Collado (2007: 71) y a entrevistas a dirigentes garífunas en los Estados Unidos. Durante 2009 y 2010, varias organizaciones garífunas realizaron una campaña entre los residentes en Estados Unidos para que respondieran a la pregunta censal de 2010 identificándose como garífunas y no como negros o hispanos. (www.garífunaheritagefoundation.org). No conocemos cuál fue el resultado de dicha iniciativa, pero se siguen manejando cifras aproximadas sobre el numero de garífunas residentes en los EE.UU.

3 Según cifras del Sistema de Integración Centroamericano (SICA), para el 2010 las poblaciones totales de los países con presencia garífuna serían: Belice: 310.000; Guatemala: 14’000.000; Honduras: 7’600.000; Nicaragua: 5’800.000. 
de su territorialización y en su presencia más reciente en Estados Unidos. La multiplicidad de representaciones y auto-representaciones sobre qué es ser garífuna sigue expresándose hasta su afirmación actual como parte de la diáspora Afrodescendiente de las Américas.

Los garífuna adquieren una notoriedad significativa en el contexto actual de reconocimiento de la diversidad cultural y del multiculturalismo institucionalizado dentro de los cuatro países de América Central antes mencionados. Esta población ha jugado un importante papel en las políticas de visibilización de los pueblos de origen africano por la vía del reforzamiento de las categorizaciones etno-raciales (siguiendo, en general, las pautas del modelo aplicado a los pueblos indígenas). Este protagonismo ha implicado, con particularidades en cada país, su caracterización oficial como "grupo étnico", la incorporación de sus expresiones culturales como parte de la identidad nacional, y el reconocimiento de su cultura como patrimonio universal cultural intangible de la humanidad. ${ }^{4}$

Apoyados en un discurso sobre sus raíces caribes-arawaks y la permanencia de algunas de sus expresiones culturales, los garífuna han sido identificados y ellos mismos han reivindicado en ciertos momentos de su historia la condición de pueblo indígena. Actualmente, los procesos de movilización política de los garífuna articulan un discurso de inclusión en las sociedades nacionales, a la vez que proclaman su identidad transnacional en tanto garífunas e integrantes de la diáspora Afrodescendiente de las Américas. Esta particularidad los diferencia de otros procesos de reivindicación identitaria de bases etno-raciales en las Américas, como es el caso de los pueblos indígenas y los demás Afrodescendientes. La flexibilidad de movilizar varios registros identitarios de forma sucesiva, y a veces simultánea, les posibilita un mayor margen de maniobra en la articulación de sus reivindicaciones en los contextos nacionales y transnacionales.

Estas dinámicas de inclusión de los garífuna coexisten e interactúan con factores que, basados también en un ordenamiento racial estructural que hunde sus raíces en el periodo colonial, mantienen formas de exclusión social y discriminación en contra de estas poblaciones y fuertemente interiorizados por las sociedades nacionales, aunque no desprovistos de transformaciones.

4 Establecido por la UNESCO en 2001. 
En este orden de ideas, el propósito de este artículo es el de presentar, partiendo de una perspectiva histórica, la dinámica de la construcción de las identidades garífunas, los actores que intervienen en dichos procesos y su dinámica política. En este documento se explicitarán las articulaciones y tensiones que se presentan, por un lado, entre la afirmación de la diferencia a través de su categorización etno-racial y, por otro, su integración plena en las sociedades nacionales, articulada con su afirmación de comunidad transnacional. Para lograr este objetivo, se hará una contextualización histórica y regional y, más adelante, se expondrán los rasgos distintivos y fundamentales de las dinámicas propias de cada contexto nacional, incluyendo el de Estados Unidos.

\section{Avatares de la categorización racial. De africanos a caribes negros}

En general, las descripciones, relatos, y documentos del periodo colonial se refieren a los africanos en las Américas como negros o esclavos, o como salvajes o cimarrones en el caso de los que resistían y lograban huir de la esclavitud. La posibilidad de nombrar y caracterizar bajo la denominación de caribes negros, por parte de los actores coloniales, es la constatación de la transformación significativa y del surgimiento de un nuevo grupo humano que no impedía, sin embargo, volver recurrentemente a la categoría clásica de esclavo en fuga, negro, salvaje, etc. Según González (2008, p. xv), garifuna es una transformación de kalinago, nombre con el que los españoles denominaron a los pueblos que encontraron en las Antillas menores, a su llegada a la región desde 1492, a partir de la forma como estos pueblos se autonombraban. Pero el término "caribe" fue usado desde principios del siglo XVI para definir a los "indios salvajes" de las Antillas. La relación lingüística entre kalinago y caribe da paso a la palabra caníbal (que significa antropófago); expresión que fue usada casi como un sinónimo en ciertos periodos durante la Colonia, y posteriormente en estudios sobre los pueblos con la denominación genérica de caribes (Taylor, 1958). Según Breton (1665) los pobladores de las Antillas menores se autonombraban calliponan, calinago o carinaco, que se transformó en Callina, Karina Karibe, Galibi hasta llegar a Garifuna o Garinagu.

En las Antillas, pobladas inicialmente por indígenas, la presencia temprana (desde mediados del siglo XVI) de europeos y africanos va a forjar una 
dinámica de mestizaje que deriva en varias formas en las diferentes islas. Para el caso de la isla de San Vicente, los relatos de la historia garífuna registran la llegada de los primeros africanos para 1635, luego del naufragio cerca de la isla de dos barcos españoles que transportaban esclavos con la subsiguiente huida de los africanos hacia alli. ${ }^{5}$ Sobre la presencia indígena en las islas, la versión más aceptada se apoya en descripciones de viajeros, religiosos, y registros coloniales ingleses y franceses que se refieren a las migraciones hacia las Antillas, anteriores a la presencia colonial europea, por parte de los pueblos arawak y caribes procedentes de la amazonía del sur del continente americano. ${ }^{6}$ Según estas mismas fuentes, hacia inicios del siglo XVIII, en San Vicente, el fenotipo negro se convirtió en el predominante, sin que desapareciera un grupo de indígenas caribes también llamados caribes rojos o amarillos, que se convirtió en minoritario. ${ }^{7}$

Las crónicas de autoridades coloniales, misioneros y exploradores siguen siendo los elementos a partir de los que se reconstruye la historia de los africanos, de los indígenas, y la vida de los caribes negros en San Vicente. ${ }^{8}$ Estos relatos registran fuertes interacciones entre indígenas caribes, emisarios religiosos, colonos, militares (básicamente ingleses y franceses), y africanos de diferentes condiciones, como los fugitivos de naufragios de barcos negreros, de las islas vecinas y algunos que llegaron como esclavos. Las descripciones sobre los aspectos de la vida de los caribes negros en San Vicente denotan una intensa dinámica de circulación entre las Antillas menores de actividades de comercio técnicas agrícolas y de navegación, capacidades de negociación y de alianzas, así como de aptitudes militares reconocidas por las autoridades coloniales y por los colonos. Uno de los aspectos que despierta interés en algunos de los

5 Rey (2005: 60) cita una referencia de Calendar of States Papers (1880) británico, que se refería, en 1635, a San Vicente como una isla habitada por indios y algunos negros sobrevivientes de dos naufragios de barcos españoles.

6 En términos generales, los estudios etnohistóricos más reconocidos sobre los garífuna, coinciden en estas versiones. (Ver por ejemplo Conzemius, 1928; Taylor, 1951; Cohelo, 1955; Beaucage, 1970; Davidson, 1974; Gullik, 1976; González, 1988).

7 Los indígenas arawuak habían desaparecido en el proceso de confrontación y mestizaje con los caribes, quedando elementos varios de su cultura, en particular en la lengua (Cohelo, 1995: 25), (González, 2008: 58).

8 Entre las principales fuentes usadas por los estudios históricos y antropológicos: Breton, 1665; Labat, 1722; Du Tertre, 1667-1671; Burton, 1685); Young, 1795; Calendar of State Papers, de 1574 a 1733. 
narradores de la época consiste en las prácticas rituales relacionadas con los muertos y la enfermedad, hoy llamadas genéricamente como "culto a los ancestros". Con todas las transformaciones que han tenido estas prácticas, ellas siguen siendo actualmente uno de los elementos cohesionadores de su identificación como grupo.

El predominio fenotípico que alcanzan los elementos africanos en dicho proceso de mestizaje se puede explicar por el factor demográfico. La presencia de africanos de diversas procedencias del Caribe fue aumentando gradualmente hasta sobrepasar ampliamente en número a los indígenas. ${ }^{10}$ Por otro lado, la supremacía de factores culturales amerindios, como la lengua y algunas prácticas productivas, tendría que ver con una mayor adaptación y dominio del medio geográfico de estos pueblos caribes y arawaks en las Antillas desde tiempos bien anteriores a los del inicio de la llegada de africanos. Taylor (1951: 143) hablaba de la cultura garífuna como un "pastel negro compuesto esencialmente de ingredientes amerindios" (citado en González, 2008: xxv). González (2008: xxvi) insiste en la gran capacidad de adaptación de los africanos y la rápida construcción de formas culturales nuevas. Esta interpretación vendría a acercarse a las hipótesis de Mintz y Price (1992 [1976]) cuando plantean que, en América, las poblaciones de origen africano construyen formas culturales nuevas en las que lo africano se manifiesta a través de rasgos o fragmentos que no son siempre explícitos.

Las Antillas menores fueron un territorio disputado, básicamente, entre franceses e ingleses. San Vicente fue durante buena parte del periodo colonial un territorio de predominancia Caribe debido a la tenaz resistencia ejercida por éstos, tanto en su periodo de indios caribes como posteriormente en tanto caribes negros y rojos. Esto en medio de tratados, acuerdos, y una presencia colonial menor con procesos embrionarios de plantaciones e intercambios comerciales y laborales con los nativos; acompañada de tensiones y periodos de abierta hostilidad. En el contexto de la competencia anglo-francesa, la isla queda bajo dominio inglés en 1763. Se inicia entonces un arduo proceso

9 La confluencia entre los elementos comunes en las prácticas religiosas y sus transformaciones están documentadas en los relatos y crónicas, en particular de los misioneros en San Vicente, y desde mediados del siglo XX en las etnografías clásicas citadas.

10 Para 1683 se estimaba la presencia en la isla de 4.000 negros y 2.000 indígenas (Archives nacionales, Basse-Terre. Col. C8A12, f. 251. De Blénag et Bégon, “Mémoire pour le roi...” citado por Rey, 2005: 65). 
de negociaciones y confrontaciones entre la vocación inglesa de afirmar su poder colonial sobre la isla y la pretensión de los caribes negros y rojos de preservar sus tierras (González, 2008: 48).

En 1795 las hostilidades se generalizaron y se inicia lo que se conoce como Guerra Caribe. A mediados de 1796, las fuerzas caribes se rinden ante los ingleses. En este contexto muere el jefe y héroe mítico de la resistencia garífuna, Chatoyer (Beauçage, 1970; Cohelo, 1995: 44) sobre quien se construyen relatos heroicos que hoy son parte del discurso político memorial del movimiento garífuna. Los caribes fueron deportados a Baliceaux (otra isla de la región bajo el dominio inglés) y de allí retornaron a San Vicente los pocos caribes rojos que habían sido capturados, mientras que los negros eran deportados hacia las islas de Roatán, en la actual Honduras.

Esta primera fase de conformación de los caribes negros como grupo humano diferenciado se da en un contexto de conflictos coloniales y de guerra, pero también de alianzas, negociaciones y adaptaciones, a veces voluntarias y otras forzadas. Esta experiencia histórica acumulada, junto con la deportación hacia América Central, será el telón de fondo del escenario en el cual los caribes negros van a continuar su proceso permanente de construcciones identitarias.

\section{Asentamiento transnacional en América central. ¿Quiénes son los que llegaron?}

Según fuentes históricas citadas por González (2008: 48 y 50), los caribes negros llegan a la isla de Roatán ${ }^{11}$ el 11 de abril de 1797, desembarcando 2.026 garífunas. Al poco tiempo pasan al puerto continental de Trujillo y los hombres van a ser adscritos a las milicias, bajo el mando de los españoles para la defensa del fuerte de los ataques ingleses.

Cuando los caribes llegan a Trujillo, allí ya se encontraban, desde 1796, aproximadamente unos 300 "negros franceses" provenientes de Santo Domingo,

11 Roatán es una de las Islas de la Bahía frente a las costas de lo que es hoy Honduras, pero que en el momento del desembarque hacía parte del la Capitanía General de Guatemala bajo dominio colonial español. 
todo ello en el contexto del conflicto que da origen a la independencia de Haiti. ${ }^{12}$ Las hipótesis de los estudios sobre la presencia garífuna en América Central, su expansión demográfica, y su poblamiento a lo largo de la costa centroamericana presentan la idea de un proceso gradual de fusión de los negros franceses con los caribes negros. Pero el proceso de relaciones entre ambas poblaciones necesita de mejor trabajo de investigación histórica, igual que las demás dinámicas de mestizaje en las que los garífuna van a intervenir a lo largo de sus procesos de dispersión por Centroamérica. Se podría intuir que el tránsito de los 2.026 caribes negros que desembarcan en Roatán a los aproximadamente 400.000 que se contabilizan actualmente no puede explicarse exclusivamente por una dinámica de crecimiento poblacional endógeno de los garífuna. Sin embargo, la preeminencia continua hasta el presente de rasgos fenotípicos negros y la permanencia de rasgos culturales hace pensar en una tendencia contraria, es decir, en un proceso en el que las dinámicas de mestizaje con grupos de población con los que han cohabitado en América Central han sido poco significativas. ${ }^{13}$

Las relaciones entre españoles y caribes negros van a estar acompañadas de muchas oscilaciones. Inicialmente fueron recibidos como guerreros competentes, dotados de capacidades en agricultura, comercio y navegación, y con un odio "natural" a los ingleses; No obstante, a los pocos años pasan a ser considerados como una amenaza a causa de sus ideas libertarias, que ejercían una mala influencia sobre los negros aun esclavizados. Autoridades españolas llegan a exigir su expulsión, ${ }^{14}$ que luego se transformó en una política de dispersión hacia el resto de la costa de Honduras y hacia la Mosquitia. ${ }^{15}$

El proceso inicial de dispersión y asentamiento de los garífuna se da en medio de las disputas por las costas caribes de la región entre ingleses y los

12 Los trabajos históricos y las crónicas sobre los antecedentes de la llegada de los "negros franceses", y su transformación en milicias al servicio de los españoles, a América Central, así como su presencia en el Caribe dominado por los españoles, está documentada en varios estudios. Ver, por ejemplo, Houdaille (1954), Rey (2005), Victoria (2006).

13 Si nos atenemos a los estudios etnohistóricos existentes, el único proceso de mestizaje de los garífunas con otros grupos negros fue el que se dio con los “negros franceses" en el momento de su llegada a América Central.

14 Informe de Ramón Anguiano (1813) en el Archivo General de Centroamérica. Citado por González (2008: 94).

15 Región costera entre Nicaragua y Honduras habitada mayoritariamente por indios Miskitos, hostiles a los españoles y proclives a establecer relaciones con los ingleses. 
españoles. Estos habían asentado su poder en el interior continental, pero no lograban consolidarse en las partes costeras en medio del asedio inglés, de la resistencia de indígenas y de una presencia significativa de negros de distintas procedencias: los creoles (de las Antillas mayores que habían comenzado a estar presentes al mismo tiempo que se inicia la presencia colonial inglesa desde los años 1640), los negros franceses y los caribes negros a fines del siglo XVIII.

A pesar de que las dinámicas de movilidad garífuna han continuado hasta el último proceso migratorio hacia los Estados Unidos, se puede decir que a partir de los años 1830 la territorialización en Centroamérica ya tenía un perfil definido. ${ }^{16}$ Los estudios etnográficos e históricos referenciados coinciden en sus rasgos fundamentales respecto el proceso de poblamiento garífuna en América Central. En general, se trata de procesos migratorios graduales e irregulares, con idas y venidas hacia los primeros territorios de asentamiento, y cambios de lugar generados por diversas razones, hasta que se va consolidando el poblamiento de los nuevos espacios ocupados. Los discursos memoriales de los garífuna acerca de la gesta de su dispersión y territorialización se concentran en las historia de los jefes de grupos que dirigieron los procesos migratorios, y que hoy son objeto de un culto memorial como héroes de la génesis garífuna y fundadores de sus poblados en cada país.

A partir de 1820, ni la Independencia de América Central de los españoles o la posterior delimitación de fronteras nacionales afectaron de forma sustancial esta movilidad. Los nuevos países tuvieron que seguir confrontados a la presencia inglesa en la Mosquitia y la Honduras británica, hoy Belice. La dinámica de movilidad transnacional se apoyaba en el débil control de los nacientes Estados de sus fronteras marítimas y la continua búsqueda de mejores oportunidades productivas, laborales y de vida. Los lazos familiares de los garífuna ya estaban tejidos en la trama transnacional y aún hoy continúan vigentes para las celebraciones rituales y las fiestas en las que se activan los vínculos filiales, pues las ceremonias rituales convocan los grupos de familias extendidas con presencia en los diferentes países. Mario Ellington, líder garífuna guatemalteco manifiesta en una entrevista "ahora que con lo de la globalización se habla tanto

16 Beaucage (1970) y Davidson (1979), quien habla de 70 poblados garífunas en la costa de los cuatro países, de los cuales la absoluta mayoría se encontraba en Honduras. González (2008: 103) indica otras áreas de colonización posterior para Honduras. 
del borramiento de fronteras y la gran movilidad de la gente de un país a otro, pues los garífuna eso lo venimos practicando desde que existimos como pueblo y, a pesar de todos los problemas, no hemos parado hasta el presente". ${ }^{17}$

Desde la llegada garífuna a Centroamérica, hasta la consolidación de su dispersión transnacional, se van a presentar variantes en la forma de representación y las apelaciones etno-raciales utilizadas. La utilización de los vocablos garífuna y garinagu era habitual como una forma de auto-apelación en el uso de su lengua, pero en español o en inglés siempre se auto-representaban como caribes o como negros tal como eran tratados por españoles e ingleses. La declaración de un jefe garífuna llamado Jack, recogida por emisarios de las autoridades españolas en Roatán a su llegada en 1797, registra el uso del término caribe como forma de autonombrarse: "No mando en nombre de nadie. No soy inglés ni francés ni español, ni me importa serlo. Soy caribe, un caribe que no esta subordinado a nadie. No quiero ser más de lo que soy ni tener más de lo que tengo". ${ }^{18}$

González (2008: 107) refiere que en los registros de la Iglesia católica del siglo XIX se los calificaba como "morenos", "caribes morenos", "morenos franceses" o "caribes pardos". En 1825, la primera Constitución nacional de Honduras se refiere a ellos como morenos libres (Vincensini, 2006: 18). Para ciertos efectos los garífuna eran tratados de forma diferenciada a los demás negros (básicamente los creoles), resaltando su capacidad de trabajo y sus dotes militares. En otras situaciones simplemente hacían parte de los negros que había que controlar, expulsar, etc.

Diversas investigaciones etnohistoricas en Honduras $^{19}$ y Guatemala muestran cómo durante el siglo XIX se transitó indistintamente entre las identificaciones de negros, caribes, caribes negros, y finalmente morenos. Según Cohelo, ${ }^{20}$ en Honduras la principal preocupación de los garífuna era que no se les asignara un pasado esclavo: "los morenos no quieren ser llamados negros". Anderson (2008) también ahonda en otros ejemplos sobre esto, lo que coincide con los relatos recogidos por Palacio (2005) en Belice. La

\footnotetext{
17 Entrevista Mario Ellington, 2008.

18 Gaceta de Guatemala, junio 26 de 1797.

19 Entre ellas (Amaya, 2007), (Euraque, 2004).

20 Notas de campo para su investigación doctoral, Cohelo (1955) citado por Anderson (2008).
} 
búsqueda de diferenciación con los creoles (negros), a los que los garífuna les asignaban un pasado de esclavos, se acrecienta también con las tensiones que se registran desde el periodo colonial en la competencia por recursos, tierras, y oportunidades de trabajo en Belice y la Mosquitia. Luego, durante la primera mitad del siglo XX van a ser recurrentes las fricciones entre los morenos (garífunas) y los negros (los que migran de las Antillas buscando trabajo o traídos por las compañías bananeras) en toda el área de poblamiento alrededor de las plantaciones bananeras.

En el caso de los garífuna, la circulación de categorías raciales ha tenido diversas variantes que transitan desde la Colonia a la fase de construcción nacional en Centroamérica. En este proceso interactuaron las elites en el poder y las mismas poblaciones garífunas. Las variaciones de categorías de un país a otro, de un periodo a otro, y también en función de las coyunturas políticas y económicas van a fluctuar permanentemente.

Sin embargo, el peso de la apelación a lo negro, ligado explícitamente o no a la descendencia africana ha predominado frente a la caracterización de los garífuna como amerindios. Esto no significa que estemos ante un alineamiento de lo racial entendido como un enfoque simplemente biológico y de apariencias físicas. Cuando se habla de negros en el contexto descrito se hace alusión también a las formas culturales que se asocian con esta condición de color. ${ }^{21}$ Para el caso de los garífuna, la excepcionalidad frente a otros grupos de descendientes africanos en el continente se construye basada en la evidencia histórica de su origen amerindio y en el hecho de haber guardado una lengua, y que ésta, según lo demuestran los estudios, se caracterice como predominantemente amerindia. Pero esto no basta para que la mirada del otro los incluya espontáneamente del lado de los indígenas, ni para que los propios garífunas se asignen una única forma de identificación.

\section{Procesos políticos de identificación. La multiplicidad de ser Garífuna}

En términos generales, podemos ubicar entre los años 1960 y 1970 el tránsito de la identificación como negros, caribes negros o morenos hacia la generalización del término garifuna. Esto es observable tanto en los estudios sobre este grupo

21 Sobre la superoposición entre raza y etniciad para el conjunto de América Latina, ver Wade (2000). Anderson (2007) también se apoya en esta percepción sobre la imbricación de raza y etnicidad en el caso garífuna. 
de población, como de parte de otros actores sociales que son avocados a nombrarlos. ${ }^{22}$ Los mismos garífunas adoptarán esta forma de autoidentificación, ya no solo al usarla en su lengua, sino también en los idiomas nacionales (inglés y español) de los países en los que están presentes.

Pero este salto hacia una categorización que podríamos llamar más "étnica" o "cultural" no ha hecho desaparecer el recurrente uso genérico de negro que los asimila con el resto de poblaciones de origen africano. Dicha asimilación va de la mano con sus rasgos fenotípicos africanos, pero también con las representaciones sobre unas características de formas de vida y comportamiento que se les asigna o que los mismos garífunas asumen a través de su afirmación identitaria. Todo esto salpicado también por la identificación más episódica de los garífuna como indígenas, que va a darse en ciertos contextos y de su reivindicación como ciudadanos de cada uno de los cuatro países centroamericanos en los que se encuentran.

González (1979) reporta que el salto de caribes negros hacia garífunas se da en el marco de un proceso de politización bajo la influencia del movimiento negro en los Estados Unidos vía los emigrantes garífunas en un proceso que asocia lo garífuna primero con los movimientos contra la discriminación racial y luego da paso a reivindicación de la raíces africanas y, en menor medida, amerindias. En este caso estaríamos frente a un modelo de etnicización común por el que pasaron varios movimientos negros en América Latina y el Caribe. Señalando siempre la particularidad de su variante de reivindicación como amerindios que ha surgido en varios periodos de su historia y al cual nos referiremos mas adelante.

Sin embargo, una mirada a las formas en que la afirmación identitaria era utilizada en la acción política de los garífuna muestra que ellas han estado determinadas por las situaciones concretas que se fueron gestando en cada país centroamericano, las que condicionaban sus dinámicas de participación política y social, y los niveles que alcanzaban las formas y expresiones de inclusión o reconocimiento. Es decir, las formas de acción política no se pueden explicar a partir del contexto exterior y de las influencias del movimiento negro en Estados Unidos, pues para el caso garífuna existe un

22 En los estudios académicos citados en este texto también se evidencian estos cambios en la terminología usada y se transita de Caribes negros a Garífuna - Garinagu. 
nivel intermedio entre lo transnacional y lo nacional. Esto tiene relación directa con sus reivindicaciones como ciudadanos de cada país en el que se han asentado, articulado ello con su transnacionalidad como pueblo garífuna, la importancia de su presencia en los Estados Unidos, y con las dinámicas políticas que se desprenden de esta múltiple localización.

$\mathrm{Al}$ respecto, recordemos que la gran mayoría de sociedades centroamericanas han sido consideradas como espacios en los que se entronizó al modelo, casi monopólico para toda América Latina y el Caribe, de naciones y repúblicas producto del mestizaje indoeuropeo, que dejaba por fuera a los negros de la gestación de las naciones centroamericanas. Se pretendía borrar el hecho histórico de la presencia significativa, y por momentos mayoritaria, de esclavos, negros libres, y mulatos en el mestizaje de la región (Gundmunson, 2009; Cáceres, 2008; Lizcano, 1993). A esta realidad colonial se suma la llegada de los garífuna y antillanos, en medio de la pugna por el control de las costas caribes entre ingleses, españoles, y luego con los nacientes gobiernos nacionales.

Existen otras situaciones que contrastan con el pretendido modelo homogéneo de naciones mestizas indoeuropeas en el que se encasilla Centroamérica. Se presenta la particularidad del proceso de construcción social y política del territorio del actual Belice, antigua colonia británica y país independiente desde 1981, donde tanto el modelo colonial como las formas que asume el nuevo Estado nacional surgen de la colonización inglesa y donde la población de origen africano fue mayoritaria hasta apenas hace dos décadas. ${ }^{23}$ Por otro lado, la región de la Mosquitia, en las costas limítrofes de Honduras y Nicaragua y en general el conjunto del caribe nicaragüense, también tiene sus particularidades políticas e históricas. Esta región se caracterizó por una presencia intermitente de colonialismo inglés, fuerte presencia indígena y creole, y débil control de las autoridades, en primer momento españolas durante la Colonia y, posteriormente, de parte de los gobiernos nacionales luego de la independencia.

23 Esto se explica por la presencia de una cantidad significativa de esclavos traídos de las Antillas para el trabajo de extracción maderera, principal fuente de recursos de la zona hasta los años 1930-40. El territorio de lo que hoy es Belice está constituido por una amplia área costera, plana en el norte y un importante macizo montañoso boscoso en el sur. La presencia de colonos europeos fue mínima y buena parte de la administración colonial se ejercía desde Jamaica. Su territorio estuvo en disputa con Guatemala hasta finales del siglo XX. Belice cuenta con una población de aproximadamente 300.000 habitantes (Registros del año 2000). 
Estos elementos problematizan la visión de nacionalismo mestizo generalizado con que se caracteriza a esta región y ayudan a explicar las formas diferenciadas que va tomando la presencia garífuna en las distintas sociedades nacionales, sus formas de afirmación identitaria, y la acción política asociada a dichas mecanismos de representación.

\section{Los garífuna de Belice. Un reconocimiento precoz}

Para el caso de Belice, los garífunas logran un significativo nivel de incidencia política y de reconocimiento que se explica por el contexto nacional especifico. En ese país, la población creole (descendientes de africanos llevados como mano de obra esclava de ingleses) se fue consolidando como mayoritaria. Hacia la primera mitad de los años 1960, ${ }^{24}$ los creoles comenzaron a contar, gradualmente, con mecanismos de ascenso social y espacios de reconocimiento de parte de la administración colonial; finalmente asumen el control del nuevo Estado independiente a partir de 1981. Los garífuna, aun en medio de las tensiones que enfrentaron a su llegada con la administración y los colonos ingleses, y luego con los creoles en el siglo XIX, también lograron obtener reconocimiento, posibilidades de ascenso social, y participación en puestos de representación política y responsabilidades gubernamentales.

Desde los años 1920 se registra la existencia de organizaciones reivindicativas de la identidad garífuna en Belice, aunque asumiendo la denominación de organizaciones Caribes. El 19 de noviembre de 1941, la Carib Developpment Society, organización creada por el líder garífuna Thomas Vincent Ramos, ${ }^{25}$ promueve la celebración de la llegada garífuna a territorio beliceño en Dangriga. Se trata del primer Carib Disembarkment Day, que contó con la autorización de las autoridades coloniales. Tres años más tarde fue declarado día de fiesta en los poblados del sur del territorio donde la mayoría de sus habitantes son garífunas. Mas tarde, esta fecha se convierte en el Garifuna Settlement Day. Desde 1977, sin ser aun Belice un país independiente, ${ }^{26}$ es declarada fiesta nacional (Cayetano, 1996: 35; Izard,

24 Establecimiento de formas de autogobierno bajo tutela inglesa.

25 T. V. Ramos es una figura muy importante en el discurso del actual movimiento garífuna de Belice. Su gesta lo pone al lado del legendario líder de la resistencia contra los ingleses en Saint Vincent, Chatoyer, y de Alejo Beni, guía del grupo fundador de Dangriga en 1823. Ramos fue activo militante por la independencia de Belice, junto con los grupos creoles que reivindicaban esta bandera desde 1920 .

26 Belice alcanza su independencia definitiva el 1981, pero desde los años 1960 va adquiriendo niveles 
2003; Arrivillaga, 2005: 76). La principal celebración se continúa realizando en Dangriga con presencia de dignatarios del gobierno nacional. La historia y la cultura garífuna son reivindicadas en el discurso oficial como parte del patrimonio nacional beliceño y tomada como ejemplo para las poblaciones creoles. ${ }^{27}$

El Settlement Day es una representación dramatizada de la llegada, desde Honduras a Belice, de algunos de los principales productos agrícolas que consumen los garífuna. Posteriormente, las organizaciones de los demás países de América Central con presencia garífuna van a adaptar esta celebración a sus respectivas historias nacionales, vinculándola con su procedencia de San Vicente y tomando el nombre de Yurumein (San Vicente en lengua garífuna). La movilización para reconocer el legado histórico y la cultura garífuna en Belice no negaba sus orígenes amerindios, pero Ramos, el líder mas visible de este proceso desde los años 1920, fue también miembro activo de la UNIA, ${ }^{28}$ y su lucha por las reivindicaciones de los garífuna estaba asociada a las consignas del garveyismo frente a las poblaciones del origen africano en las Américas (Izard, 2003; Palacio, 2005).

En 1980, el National Garífuna Council (NGC) ${ }^{29}$ plantea la reivindicación de una doble herencia cultural: la africana y la amerindia. En este periodo se van a desarrollar varias iniciativas de inclusión de los garífuna a movimientos nacionales y transnacionales indígenas, en los cuales los cuales finalmente lograrán su inclusión (Palacio, 2005: 44-49). La importancia que toma desde 1970 en el contexto internacional el reconocimiento de los derechos y la cultura de los pueblos indígenas es uno de los factores que explica por qué para los garífuna se volvió importante explicitar su herencia amerindia. El NGC retoma la celebración del Settlement Day como uno de los elementos centrales de su reivindicación memorial, cultural y como bandera de movilización política. En el contexto beliceño se trata de una reivindicación de sus orígenes y de su cultura diferenciada de los otros grupos étnicos presentes en el territorio (creoles e indígenas mayas), pero también como expresión de su carácter de

graduales de autonomía. El país es miembro de la Commonwealth desde su independencia.

27 En la celebración del Settement Day en 2008, el primer ministro llamaba a la población de Belice a retomar el ejemplo del pueblo garífuna en materia de defensa de su cultura y su memoria (Discurso del primer Ministro; Dangriga Noviembre 19, 2008).

28 United Negro Improvement Association - Movimiento creado por Marcus Garvey.

29 Ella es la principal organización garífuna de Belice, surgida en 1981. 
constructores de la nación beliceña.

Para 1990, en Belice surge la iniciativa de conformar una coordinación de movimientos negros de América Central que incluyera a las organizaciones garífunas y al conjunto de movimientos de Afrodescendientes en la región. La iniciativa surge del NGC en compañía de la Organización de Desarrollo Comunitario (ODECO). ${ }^{30}$ Luego se van a adherir otros movimientos negros de los demás países centroamericanos, ampliando el proceso de unidad y construcción política desde "lo garífuna" hacia las organizaciones negras.

Este giro tiene que ver con el hecho de que, desde finales de los años 1980 , se comienzan a presentar en el contexto internacional, con sus réplicas en algunos países latinoamericanos, la inclusión de las poblaciones negras al lado de las indígenas en el marco de las políticas multiculturales en boga. De ahí la renovada fuerza que adquiere para los garífuna el acento en su Afrodescendencia. Con ello, a la vez que se ubica claramente como parte del movimiento negro centroamericano, el NGC inicia el trabajo de preparación del dossier ante la Unesco para el reconocimiento de la cultura garífuna como pieza del patrimonio intangible de la humanidad. Esta iniciativa contó con el aval del gobierno de Belice, y el apoyo posteriormente de Guatemala, Honduras y Nicaragua. Esta candidatura fue aceptada en 2001, constituyéndose así en un elemento nuevo de legitimación de los movimientos garífunas y en un insumo más dentro de su discurso de exigencia de derechos (Cayetano, 2005; Izard, 2003).

El caso beliceño muestra la búsqueda de equilibrios entre identificaciones múltiples. Estas comprenden lo garífuna como pueblo amerindio, lo cual es reivindicado cuando logran su inclusión en los procesos de movilización transnacional de los pueblos indígenas en 1970 (Palacio, 2005). No obstante, el proceso posterior a la creación de la ONECA, en los 90', los pone con más énfasis del lado de lo Afro y lo negro. Además, a pesar de la reivindicación que asumen como pueblo transnacional, y ahora parte de la diáspora Afrodescendiente de las Américas, su pertenencia nacional como beliceños es también una parte fundamental de su discurso, manteniendo un rol importante en los asuntos políticos de su país.

30 Movimiento garífuna hondureño. 


\section{Honduras. Diversidad de luchas y reconocimiento político}

Honduras es el país con mayor población garífuna, ${ }^{31}$ la cual se extendió a todo lo largo de su costa caribeña. El activismo político garífuna, en el que se incluyen sus reivindicaciones sociales articuladas a su identidad como pueblo, tiene sus referentes contemporáneos en la creación de la Organización Fraternal Negra de Honduras (OFRANEH), en 1977. ${ }^{32}$ Otros movimientos y asociaciones continuarían surgiendo, y casi todos tendrán origen en fraccionamientos y nuevas tendencias surgidas en el seno de la OFRANEH. La más visible de todas estas es la Organización de Desarrollo Comunitario (ODECO), que es creada en 1992, y centra su discurso en la Afrodescendencia del pueblo garífuna y su inclusión en la diáspora africana de las Américas, colocándose así en la tendencia contemporánea mayoritaria de los movimientos negros en América Latina.

La actividad política de los garífuna en Honduras se enmarca inicialmente en la participación en los bandos que se enfrentaron durante el siglo XIX en el marco de los procesos de construcción nacional. ${ }^{33}$ Durante el siglo XX los garífuna contaron con importantes espacios de representación política en las regiones de la costa alineados mayoritariamente con el Partido Liberal. ${ }^{34}$ Entre los años 20 y 30 , los garífuna podían elegir autoridades locales y regionales, y contaban con jefes militares regionales y representantes al parlamento (Cohelo, 1955).

En 1937, bajo una dictadura militar, la comunidad garífuna de San Juan fue acusada de complot junto al Partido Liberal. Como escarmiento, todos los hombres dela aldea fueron fusilados. Actualmente, la masacre de 1937 es un hecho reivindicado como una parte importante de la memoria y de la historia entre los intelectuales y lideres garífunas. ${ }^{35}$ Otro elemento inscrito en la memoria del movimiento garífuna

31 En cifras absolutas, serían el 90\% de la totalidad de garífunas que habitan América Central (unas 200.000 personas). En porcentaje total de la población hondureña representan el 2\%, según cifras del Instituto Nacional de Estadística de ese país.

32 Esta rganización nace en 1977 en una posición de lucha por sus derechos.

33 Se refiere aquí a las clásicas confrontaciones entre españoles y criollos, en las que los garífunas estuvieron de ambos lados. Ya se mencionó cómo participaron en la defensa de las costas al lado de los españoles; sin embargo, también algunos van a enrolarse en las filas independentistas. Posteriormente se implican también en las pugnas entre los partidarios de la unificación centroamericana y los defensores de las autonomías por país, opción que finalmente se impondrá.

34 Durante el siglo XIX y la mitad del XX, Honduras se caracterizó, como buena parte de Latinoamérica, por el bipartidismo: Partido Conservador, que se convertirá luego el Partido Nacional y el Partido Liberal.

35 Según el intelectual garífuna Salvador Suazo, la adhesión mayoritaria de los garífuna al Partido 
como un antecedente de los procesos organizativos contemporáneos es la huelga de trabajadores en las plantaciones bananeras hondureñas de 1954, pues algunos de los líderes garífunas que fundarían la OFRANEH participaron en ella. En 1940 y 1950 varios de los garífuna que participaron en formas de resistencia política en contra de las dictaduras se asilaron en los Estados Unidos, donde conocieron las experiencias del movimiento negro de derechos civiles. Posteriormente, el Partido Liberal asume el poder en 1958, poniendo fin a un periodo de dictaduras militares y representando para la mayoría de los garífunas de Honduras una perspectiva de inclusión social y política. Varios de los fundadores de la OFRANEH dieron sus primeros pasos en la política de la mano del Partido Liberal. En 1960 empiezan a aumentar los ingresos de garífunas a la universidad (Euraque, 2004: 180-181).

En 1972 se crea el Instituto Hondureño de Turismo, que apoyaba la difusión de las danzas garífunas como parte de la cultura nacional hondureña. En ese entonces Honduras se encontraba bajo una dictadura militar, pero es en este escenario en el que se dan estos pasos de institucionalización de lo garífuna (Euraque, 2004: 169, 236). A las reivindicaciones en contra de la discriminación racial, inspiradas en parte por la influencia tomada en los Estados Unidos, se va a incorporar la lucha por los derechos territoriales y culturales garífunas. Roy Guevara, uno de los fundadores de OFRANEH, dice: "inicialmente nos inspiramos en las ideas de Luther King combinándola con el ejemplo indígena de luchar por la tierra y la cultura". 36

Los años de 1970 marcan una coyuntura de fuertes movilizaciones indígenas en América Latina, con la tierra y la cultura como reivindicaciones centrales. Las reivindicaciones de la OFRANEH van a articularse con aquellas de los indígenas hondureños, iniciándose un proceso de convergencia y de respuesta de parte del Estado que los incluía indistintamente como pueblos autóctonos.

En Honduras, los garífuna habían sido clasificados por el Estado como indígenas desde la década de 1860, cuando fueron considerados como morenos, junto a otros "indios selváticos" de la costa norte y de La Mosquitia,

Liberal estuvo relacionada con políticas de apoyo a las comunidades de los años 30 del siglo XX, y luego por el resentimiento frente la masacre de 1937. Entrevista a Salvador Suazo (Tegucigalpa, 2009; López García, 1994; Meléndez, 1997).

36 Entrevista Roy Guevara, Tegucigalpa, 2005. 
en la legislación que promovía su integración a la nación. ${ }^{37}$ La relación entre autoctonía y etnicidad es asumido como sinónimo en el caso hondureño, y por esta vía se traza un puente entre lo indígena, lo garífuna y lo negro en esta caso en particular (Anderson \& England, 2005; Anderson, 2007).

Según Roy Guevara, “en un primer momento, tuvimos que arroparnos con una identidad indígena para lograr reconocimiento en algunos espacios internacionales. Ingresamos al Consejo Internacional de Tratados Indios ${ }^{38}$ y participamos en la creación del Fondo Indígena en Naciones Unidas en 1992".39

Ya en 1990, con el tránsito hacia el reconocimiento de las poblaciones negras o de origen africano que se empieza a producir en varios organismos internacionales y en algunos países de la región, se registran transformaciones en la dinámica organizativa de los garífuna de Honduras. En particular, surgen nuevas organizaciones, como la ODECO o la seccional para Honduras de la Red Transnacional Afroamerica XXI. Estas organizaciones hacen énfasis en las raíces y la "africanidad” contemporánea de los garífuna y se incorporan a las redes de movilización transnacional de los movimientos negros de América Latina y el Caribe (Amaya, 2004; Agudelo, 2010).

Los logros alcanzados en materia de derechos territoriales son relativos. El Estado ha reconocido la legitimidad de estas reivindicaciones y algunas comunidades han logrado la obtención de títulos de propiedad. ${ }^{40}$ Los garífuna han alcanzado ciertos avances significativos respecto las formas de reconocimiento simbólico y político; a pesar de ello estos avances han sido insuficientes. Dentro de estos logros pueden citarse la declaración gubernamental, realizada en 1996, del 12 de abril ${ }^{41}$ como día de la etnia negra de Honduras, declarar al municipio de Punta Gorda, en Roatan, como Monumento Nacional, y la celebración del

37 Alvarado García, E. (1958). Legislación indigenista de Honduras. México: Instituto Indigenista Interamericano. Citado por Anderson (2005).

38 Este organismo surgió en 1974. El ingreso de OFRANEH se produce a inicios de 1980.

39 Entrevista Roy Guevara, Tegucigalpa, 2008.

40 La problemática sobre los derechos territoriales se ha vuelto muy compleja. La intervención de intereses estatales y de sectores empresariales que disputan con los garífuna la propiedad y el uso de las áreas de poblamiento para proyectos turísticos es cada vez más frecuente. A su vez no todos los movimientos garífunas le dan la misma prioridad a esta reivindicación. Sobre el tema del Caribbean Central American Research Council (CCARC), ver: http://www.ccarconline.org/ccarcenglish.htm

41 Fecha de llegada de los garífuna de San Vicente a la isla de Roatán. 
bicentenario de la llegada de los garífuna a Centroamérica ${ }^{42}$ en 1997. Además, el gobierno crea el Centro Cultural Garífuna, bajo la dirección de Crisanto Meléndez, y nombra a un garífuna como Ministro de las Etnias y a otro como Viceministro de Cultura y Artes.

En este mismo año, la ODECO pone el acento en la "institucionalización”, o proceso de ir ganando terreno en los espacios del Estado, para impulsar las transformaciones sociales y políticas reivindicadas por los garífuna. Este trabajo de "lobby e incidencia política" está acompañado de una articulación trasnacional en redes como la Organización Negra Centroamericana (ONECA) y la Alianza Estratégica de Poblaciones Afrodescendientes, argumentando que el reconocimiento de las reivindicaciones comunes de los pueblos de la diáspora negra en el ámbito internacional acrecienta y potencia la legitimidad de las luchas en la escala nacional. ${ }^{43}$

Actualmente, la reivindicación de la ODECO sobre la doble herencia indígena y africana no desaparece del discurso, pero sí adquiere un papel muy secundario frente a la fuerza de la "Afrodescendencia", a raíz de la preparación en América Latina de la conferencia de Naciones Unidas contra el racismo celebrada en Durban. ${ }^{44}$ Esta posición, aunque por el momento es mayoritaria, no es compartida unánimemente. Salvador Suazo, Viceministro de cultura en 2008 manifiesta

\begin{abstract}
Nosotros somos caribes y nuestra lengua es amerindia. No estoy de acuerdo con la denominación de Afrodescendientes, ya que de África proviene toda la humanidad. Los garífuna tenemos más espacios que los indígenas porque hemos luchado más y porque tenemos gente más capacitada para ocupar espacios destinados a los grupos indígenas en las que nosotros estamos incluidos por ser un grupo Afroindigena. Pero en los últimos años hemos ido perdiendo nuestra especificidad debido al impulso de la categoría
\end{abstract}

42 La celebración del Bicentenario de la llegada de los garífuna a Centroamérica fue un momento de reafirmación de la Afrodescendencia. Muchos símbolos que circulaban en la fiesta y el contenido de los discursos así lo confirman (Anderson y England, 2005: 254).

43 Entrevista Celeo Alvarez, La Ceiba, 2005, ODECO (2008).

44 La Conferencia de Durban y los documentos que de ella emanan en materia de reconocimiento, defensa y exigencia de derechos para las poblaciones Afrodescendientes son el hito más significativo de las movilizaciones de estos pueblos en los últimos veinte años. Las organizaciones del pueblo garífuna participaron activamente en ella y han utilizado los instrumentos que de dicho evento surgieron (conclusiones, compromisos y agenda de Durban) en pos de su movilización social y política (Agudelo, 2012). 
Afrodescendiente después de Durban. Nosotros debemos mantener nuestra doble identidad, negra e indígena, para poder estar en los espacios de reivindicaciones tanto de los indígenas como de los Afros. Es una ventaja que no estamos aprovechando bien. ${ }^{45}$

El año 2011 fue declarado por las Naciones Unidas como el año Internacional de los Afrodescendientes. En este marco se desarrollaron en América Latina diversas actividades (seminarios, foros, conferencias, etc.). Para el caso de Honduras, la ODECO coordinó la realización de un evento que llamó "Cumbre Mundial de Afrodescendientes, Desarrollo Integral Sostenible con Identidad" realizada en la Ceiba. Además del aval de varios organismos internacionales, esta iniciativa contó con el apoyo abierto del gobierno hondureño que llega al poder luego del golpe de estado de $2009 .{ }^{46}$ Otros sectores del movimiento negro estaban oponiéndose a un gobierno que consideraban ilegítimo, como por ejemplo las varias organizaciones Afrohondureñas encabezadas por la OFRANEH.

Algunos sectores del movimiento negro en América Latina cuestionaron la posición de ODECO al considerar que la realización de la Cumbre Internacional en Honduras, con el respaldo gubernamental, contribuyó a la legitimación de un gobierno originado en un golpe de Estado. Las principales organizaciones de Brasil, Colombia, Ecuador, Uruguay y América Central decidieron no participar en dicho evento. Se afianzan así divergencias políticas entre los sectores del movimiento garífuna, encabezados por la ODECO, que defienden la pertinencia de sus acercamientos con el gobierno que surge del golpe de Estado y otros sectores que, encabezados por la OFRANEH, se vinculan al movimiento de oposición al gobierno.

A pesar de estas contradicciones en materia política, el discurso garífuna hondureño está acompañado de forma genérica por reivindicaciones de pertenencia nacional que son usadas igualmente como instrumento legitimador de sus demandas frente a los respectivos gobiernos. En el discurso garífuna hondureño siempre acompaña sus exigencias al gobierno

45 Entrevista Salvador Suazo, Tegucigalpa, 2008.

46 Recuperado el 19 de julio de 2013 de http://ojs.unam.mx/index.php/archipielago/article/ viewFile/20131/19121. 
con un llamado a no olvidar la participación de los garífuna en las luchas de la Independencia, sus aportes en los procesos productivos que conformaron las líneas básicas de la economía hondureña en el siglo XIX y XX, así como su dinamismo en el seno de los partidos políticos, y hasta el papel jugado en la defensa de nación durante el conflicto armado con El Salvador en 1960. Es recurrente la articulación de una identificación como ciudadanos de su país y la identidad garífuna con el doble componente Afro e indígena. Esto los conecta a identificaciones genéricas transnacionales.

\section{Guatemala. Acción cultural e inclusión}

La mayoría de los garífuna de Guatemala habitan la ciudad caribeña de Livingston, que es poblada igualmente por mestizos, indígenas y descendientes de migrantes chinos e hindúes. Aunque son una pequeña minoría demográfica (aproximadamente 5.000 garífunas de un total de 13 millones de habitantes en Guatemala), la afirmación de su pertenencia al pueblo transnacional garífuna y la conservación de sus expresiones culturales han garantizado su inclusión entre la reconocida diversidad étnica del país, básicamente a partir de los acuerdos de paz de 1990. Al lado de los pueblos mayas y de los indígenas Xinka, los garífuna son considerados como parte de la población indígena de Guatemala que representa aproximadamente un 50\% del total de la población del país. ${ }^{47}$

Coincidiendo con los procesos en los demás países con presencia garífuna, existe una permanencia de las prácticas rituales ancestrales, el flujo transnacional en Centroamérica y, desde los años 1970, el inicio de la migración hacia Estados Unidos. La principal expresión pública de religiosidad garífuna vinculada con el catolicismo es la fiesta de San Isidro, patrono de los garífuna desde 1892. A esta fiesta se articuló la celebración de la llegada y fundación de Livingston, inspirada en lo acontecido en Belice desde 1941 con el Settlement Day. En Guatemala llamaron a esta fiesta Yurumein (San Vicente en lengua garífuna). Su representación, en el marco de la fiesta de San Isidro, expresa el sincretismo religioso ligado al catolicismo y a la celebración festiva de una singularidad frente a los "otros". Es la reivindicación de los orígenes y de la diferencia étnico-racial (Arrivillaga, 1985; Agudelo, 2009).

47 Información procedente del Censo de Población y Habitación 2002. Tomado del Informe Nacional de Desarrollo Humano, Guatemala 2005. 
Desde mediados de 1980, el Yurumein también va a realizarse en el marco de la celebración de la fundación oficial de Livingston (26 de Noviembre de 1937) ${ }^{48}$ como iniciativa de estudiantes garífunas que reivindican la memoria del fundador garífuna de Livingston, Marcos Sánchez Díaz. Surge entonces una joven elite garífuna que comienza a politizarse a través de la reivindicación identitaria. El grupo de estudiantes que inicialmente se organizó bajo el nombre de Ibimini (dulzura), dio paso al grupo Despertar Garífuna Marcos Sánchez Díaz" ${ }^{49}$ y, bajo la influencia de la ONECA, en 1995 nace la Organización Negra Guatemalteca (ONEGUA), creada por los ahora jóvenes profesionales de Despertar Garífuna Marcos Sánchez Díaz.

En 1996 se firman los acuerdos de paz en Guatemala que ponían fin al conflicto armado de las dos décadas anteriores. En ellos se hace especial énfasis en los pueblos indígenas, principales víctimas del conflicto. Los garífuna son reconocidos como parte de la diversidad étnica guatemalteca en un contexto que se nutre del proceso global de reconocimiento de la diversidad y las políticas multiculturales que se extienden por América Latina.

Por Decreto Presidencial de 1996, el 26 de Noviembre se vuelve el "Día Nacional del Garífuna". La celebración guarda los elementos básicos de una articulación entre lo religioso y la reivindicación de la memoria de los orígenes de su llegada a América Central. Esta fiesta se transforma en una celebración nacional/global articulada a las dinámicas políticas del movimiento garífuna de búsqueda de derechos a través de su reconocimiento oficial nacional y al afianzamiento de su presencia en el espacio global, como parte del movimiento Afrodescendiente transnacional. Al lado del infaltable Yurumein se encuentran actividades políticas y culturales paralelas que fortalecen su nueva doble dimensión: de celebración de la identidad garífuna y como espacio de reivindicación de derechos. El Estado, por su parte, participa afirmando su discurso de aceptación de la multiculturalidad.

La afirmación de la identidad garífuna en Guatemala está centrada en sus expresiones culturales que siguen mostrando mucha vitalidad. De lo cultural parten hacia un discurso de reivindicación social y política, y de inclusión en la

\footnotetext{
48 Hasta ese momento el poblado se conocía como Labuga (en lengua garífuna) o La Boca.

49 Arrivillaga (2006: 63).
} 
sociedad nacional, integrando sus identidades transnacionales como garífunas y Afrodescendientes a su ciudadanía guatemalteca. Según Mario Ellington:

Mi objetivo central ha sido la visibilización del pueblo garífuna de Guatemala. Los acuerdos de paz, particularmente lo que se refiere a la identidad de los pueblos indígenas, nos han ayudado mucho para retomar esta ciudadanía y ejercerla. Tenemos derecho a la ciudadanía plena guatemalteca, no solo por una cuestión romántica y de reclamo, sino en base a nuestros aportes al país. ${ }^{50}$

El Estado sigue limitando su afirmación de la multiculturalidad casi exclusivamente al plano cultural, mientras que en la agenda de inclusión social y económica sigue dejando mayoritariamente a los pueblos indígenas en condiciones de extrema pobreza.

Sobre la doble identificación Afrodescendiente e indígena, los garífuna de Guatemala han optado por privilegiar la primera en las cuestiones de autorepresentación; entretanto, la segunda ha sido enfatizada en su interacción con el Estado. Esta doble identificación no ha obstáculo para estar incluidos en la diversidad étnica reconocida por el Estado, que los catalogó como parte de los pueblos indígenas guatemaltecos. Como se puede observar, existe una ambigüedad que no plantea mayores contradicciones de parte del Estado, de los propios garífunas y los demás actores que interactúan en relación con las problemáticas étnicas.

Podemos observar cómo en el caso guatemalteco la dinamización política de los garífuna tuvo unas influencias transnacionales bien marcadas. Los ecos de las luchas de los negros en Estados Unidos, que llegaban de los migrantes en sus idas y venidas, y la creación de la ONECA en Belice fueron dos factores fundamentales que catalizaron procesos de politización. De la misma manera, la presión de la comunidad internacional jugó un papel determinante a la hora de que los acuerdos de paz hicieran un reconocimiento de derechos para los pueblos indígenas en los que se incluían a los garífuna.

50 Entrevista Mario Ellington, Guatemala, 2008. Mario Ellington fue el primer garífuna en graduarse en la facultad de Derecho de la Universidad de San Carlos. Es el principal fundador del grupo Marcos Sánchez Díaz y luego de la ONEGUA. Actualmente es miembro de la dirección de ONECA. Entre 2003 y 2007 fue miembro de la Comisión Presidencial contra el Racismo y Viceministro de Cultura entre 2007 y 2008. 


\section{En Nicaragua los garífuna no son indígenas, son Afrocaribeños}

Aunque la presencia de garífunas en la Mosquitia nicaragüense se registra desde finales del siglo XVIII, es partir de 1880 que se comienza a hablar de asentamientos consolidados en la costa sur de Nicaragua, cerca al puerto de Bluefields en la región costera llamada Laguna de Perlas. El primer poblado se llamó Saint Vincent, luego desde 1912 se fundan las comunidades de La Fe, Lauba y Orinoco, el actual y principal asentamiento. El héroe fundador de Orinoco es Joseph Sambola. Los estudios sobre esta comunidad nos presentan un relativo aislamiento en relación con los otros grupos de garífunas. Ello debido a una significativa distancia geográfica y a las dificultades de comunicación marítima entre las costas de Honduras, Guatemala y Belice (Davidson (1980: 31-47). La conservación de su identificación se produce por la vía de la continuidad histórica de sus prácticas rituales, mientras que la lengua se fue perdiendo con la muerte de las primeras generaciones. Desde 1980 se presentan contactos que van a vincular a los garífuna nicaragüenses a la dinamización de las organizaciones garífunas de los otros países, que priorizan el fortalecimiento de la identidad transnacional garífuna y estimulan la revitalización identitaria y la recuperación de la lengua. Por otra parte, las políticas de reconocimiento de parte del gobierno del Frente Sandinista de Liberación Nacional —FSLN (1979-1990)—, representaron para los garífuna nicaragüenses un espacio de inclusión como grupo étnico entre toda la diversidad cultural de la costa Caribe de este país a través de la Constitución Nacional de 1988 y del Estatuto de Autonomía de las Comunidades de la Costa Atlántica. ${ }^{51}$

Actualmente, jóvenes líderes garífunas de Nicaragua están vinculados a los organismos de dirección de la ONECA, y han creado la Asociación Afrogarífuna Nicaraguense - AGANIC-, participando en programas de revitalización de la lengua garífuna a través del apoyo de otras organizaciones como el NGC de Belice, la ONECA, y recientemente un proyecto de la

51 Llegar a esta etapa de reconocimiento de la diversidad cultural y la autonomía de las comunidades de la costa Caribe fue un proceso arduo. En éste, inicialmente los sandinistas pretendieron integrar plenamente la región del Caribe nicaragüense, que desde su conformación histórica se mantuvo aislada de los procesos de construcción nacional volcados hacia el Pacifico. Las pretensiones integradoras y centralistas de los sandinistas no consideraron las particularidades étnicas de la región. Esta política fue respondida con una fuerte resistencia de las comunidades del Caribe (en particular los miskitos, grupo mayoritario) que tomó la forma de oposición armada ligada a una confrontación general al sandinismo y apoyada por el gobierno de los Estados Unidos (Frühling, González et al., 2007). 
UNESCO en el que participaron los cuatro países centroamericanos con presencia garífuna. Entretanto, el gobierno sandinista estableció una neta diferenciación entre grupos indígenas y "comunidades étnicas", en las que se incluyen a los garífuna y a los creoles en tanto grupos Afrodescendientes.

En este contexto, y de acuerdo con la tendencia actual que prioriza el aspecto Afro de la identidad garífuna, en Nicaragua no ha pesado el debate sobre su doble identificación. Los garífuna nicaragüenses reivindican su pertenencia nacional al lado de la identidad como garífunas y Afrodescendientes a partir de su inclusión como pueblos en la Constitución Nacional y el Estatuto de Autonomía: "Antes de la llegada de los sandinistas" y la nueva constitución, nosotros no éramos reconocidos por el gobierno y ni nicaragüenses nos sentíamos". 52

\section{Migración a Estados Unidos, vitalidad identitaria y circulación}

La migración de los garífuna hacia los Estados Unidos comienza en los años de 1940. La crisis de una de sus más importantes fuentes de trabajo, el trabajo en las plantaciones bananeras, es una de las principales causas del inicio de este proceso migratorio. Según algunos de los estudios al respecto y las declaraciones de algunos garífunas entrevistados recientemente en Nueva York, ${ }^{53}$ hubo una rápida integración de las primeras generaciones de migrantes. En la coyuntura de la Segunda Guerra Mundial, los Estados Unidos absorbieron numerosa mano de obra en trabajos portuarios, flota mercante y otros servicios en los que los garífuna fueron vinculados. Algunos consideran que la habilidad de los garífuna de Belice de saber inglés, junto al hecho de no parecerse a los latinos, les permitió a estos "camuflarse" entre los negros estadounidenses e insertarse en la economía norteamericana. Por otra parte, los garífuna que no sabían inglés tenían alguna facilidad para aprenderlo en tanto ya tenían una segunda lengua además del español. Conforme a lo anterior, pudieron acceder a mejores condiciones que los demás migrantes latinoamericanos y caribeños.

52 Entrevista Kensy Sambola, líder garífuna nicaragüense. Miembro de AGANIC y de la dirección de ONECA.

*Los sandinistas se refiere al gobierno del Frente Sandinista de Liberación Nacional.

53 Mohor de Collado (2007); Gonzalez (2008); Gargallo (2000); Arrivillaga (2009); Entrevista colectiva, Nueva York, 2008. 
En diciembre de 2008, con motivo de la celebración en Nueva York de la asamblea anual de la ONECA, se pudo apreciar la presencia de muchas asociaciones garífunas radicadas en los Estados Unidos, así como su integración en el medio sindical en agremiaciones de participación política local, y vinculadas con movimientos negros norteamericanos. Esto es válido para las generaciones de migrantes hasta 1980. Según los entrevistados de esta investigación las últimas generaciones, a pesar de contar con el apoyo de unas redes de asociaciones garífunas bien establecidas, tienen más dificultades de encontrar trabajo y legalizar su situación de migrantes ilegales.

De igual forma se constata el desarrollo de redes de comercio de símbolos culturales, en particular de la música que circula ampliamente a través de une intensa red de sitios de Internet en los que se "vende" la cultura garífuna en forma de música, videos, libros, excursiones turísticas, planes de viajes de retorno a Centroamérica para las fiestas y periodos de vacaciones o por llamados para rituales, productos regionales típicos, etc. ${ }^{54}$

A lo largo de la historia de esta migración se observa el mantenimiento de la cohesión familiar y ritual. Entre los envíos de remesas que se implementan desde las primeras generaciones de migrantes se incluyen los gastos de los rituales. Según Salvador Suazo:

la presencia en Estados Unidos ha sido un factor de rescate cultural. Se ha revitalizado entre muchos sectores el uso de la lengua garífuna como factor de reconocimiento, más valorado que hablar el español. Hablar garífuna es parecerse a los migrantes africanos, y eso entre los negros de Estados Unidos da cierto reconocimiento mientras que el español es mal visto $[\ldots]^{55}$

Desde los Estados Unidos se financia la construcción de templos $\mathrm{y}$ algunos buyeis o sacerdotes que viven en Estados Unidos viajan a Centroamérica cuando sus conocimientos son solicitados. ${ }^{56}$ Esta red familiar

54 Ver por ejemplo el sitio web en internet www.garinet.com

55 Entrevista S. Suazo, Tegucigalpa (2009).

56 Los rituales siempre se implementan en la tierra de los ancestros y por ello el retorno es recurrente. Empero, no es posible determinar si se esté gestando otra mutación de las prácticas que permita la construcción de un territorio garífunas virtual en Estados Unidos. 
transnacional comenzó a construirse desde el momento mismo de la llegada a Centroamérica, y habría que agregar que desde la movilidad en las Antillas menores, esta red ya estaba siendo tejida. Las migraciones hacia los Estados Unidos amplían las dimensiones espaciales de la red. Este fenómeno se conserva y aun se puede decir que se fortalece con el aumento gradual de posibilidades de circulación entre los Estados Unidos y los países de América Central. Durante la XIII asamblea de la ONECA, realizada en Nueva York en 2008, se notó que dos temas tenían eran especialmente sobresalientes: la fuerte presencia de asociaciones y otras formas organizativas garífunas frente al resto de poblaciones negras de la región y la persistencia relatada por los garífunas entrevistados sobre el tema de la circulación, del ir y venir. Igualmente, durante las fiestas del día nacional garífuna en Livingston se ha tenido la oportunidad de hablar con varios "visitantes" garífunas que se trasladan de los Estados Unidos exclusivamente para las celebraciones.

La alta capacidad de para movilizar recursos (de capital y políticos) de los migrantes garífunas en los Estados Unidos, cohesionados por las redes familiares y rituales que los mantienen ligados a sus países de origen, ha sido un factor determinante para la dinamización política y sus objetivos de preservación cultural Estados Unidos y en Centroamérica. Los núcleos de organización básica de los primeros años tuvieron relación con sus poblados centroamericanos de origen. Las formas de organización que surgen inicialmente se referían a los grupos de garífunas que pertenecían a un poblado y realizaban acciones de recolección de fondos para actividades en su comunidad, ya fuesen religiosas (ceremonias o construcción de templos para su culto de los ancestros o ayudas para la celebración del Yurumein, San Isidro u otra fiesta religiosa), o de ayudas para infraestructura (construcción o mejoramiento de escuelas, puestos de salud, parques, etc.). Estas formas de organización aun persisten y son muy importantes en los Estados Unidos, pero en ciertos contextos se diluyen frente a otras formas de identificación que van a vincular a los garífunas de los cuatro países centroamericanos $^{57}$. Las asambleas generales de la ONECA son un espacio en el que se pueden apreciar estas dimensiones de la identificación de los garífunas. Estos encuentros son un espacio en el que se reencuentran miembros de

57 Gargallo (2002); ODECO (2008); entrevista Mirtha Colón, dirigente de ONECA en Nueva York, Belice, 2009. 
comunidades específicas en Centroamérica: los que están en los Estados Unidos y los que vienen de sus poblados. Allí tratan asuntos relativos a sus nexos de solidaridad específica. El otro nivel, más amplio, es el de la confluencia de los garífunas de un país en particular. Se nota, por ejemplo, la preponderancia de garífunas hondureños con sus reivindicaciones como ciudadanos nacionales y su poder de incidencia en el gobierno (la asamblea realizada en Nueva York en 2008 fue inaugurada por el presidente hondureño de ese momento, Manuel Zelaya). El otro nivel corresponde a la fuerza genérica de los garífunas como comunidad transnacional en Centroamérica y los Estados Unidos, y su importancia en el seno de la ONECA. Desde allí, pero yendo mas allá de este espacio regional, los garífunas reivindican su condición de pueblo Afrodescendiente vinculado a redes más globales que los relacionan con sectores del movimiento negro en América del Sur, las islas del Caribe y los Estado Unidos. Finalmente, una dimensión que va cobrando importancia en la actual coyuntura es la de hacer parte de los latinoamericanos en los Estados Unidos que se movilizan por mejorar su estatus migratorio y de residencia, entre otras reivindicaciones.

\section{La "rentabilidad" de los procesos de identificación racial y étnica de los garífuna}

Para los garífuna, el asumir a lo largo de su historia sus múltiples identificaciones parece haber dado los resultados esperados. Los esfuerzos por la conservación, revitalización y visibilización de sus expresiones culturales han sido un mecanismo de legitimación de sus demandas y reivindicaciones sociales y políticas. Es un hecho el reconocimiento oficial de los garífuna como parte de una diversidad cultural que hasta hace algunos años fue negada por el discurso nacionalista mestizo indoeuropeo que prevalecía en la región (con la particularidad del caso beliceño).

Hemos visto cómo el caso garífuna presenta un juego más complejo que para la mayoría de poblaciones negras e indígenas. Los múltiples usos de varias categorías de identificación etno-racial apelan a los orígenes y rasgos Afrodescendientes e indígenas, conectados con la afirmación ciudadana de pertenencia nacional. Esto se articula con la vinculación a redes transnacionales, tanto del entorno del movimiento indígena como de las organizaciones negras o de Afrodescendientes. 
La dinamización de los elementos culturales ligados a procesos políticos han sido una respuesta de algunos líderes y miembros de sus comunidades frente a procesos estructurales de debilitamiento, reflejados para ellos en marginalidad histórica frente las sociedades nacionales, pobreza creciente, y pérdida de territorios. Pero, a pesar de los logros en materia de reconocimiento, la superación de dichos factores estructurales no ha llegado con las políticas multiculturales de reconocimiento.

Un ejemplo de esta ambigüedad se encuentra en el uso del turismo como mecanismo de articulación entre la multiculturalidad y el desarrollo. En la práctica, los garífuna se enfrentan a una folklorización estimulada por el Estado y los empresarios privados del turismo, ávidos de mostrarle al cliente "los encantos de las culturas ancestrales al lado de los paisajes exóticos de sus costas". Esta puesta en escena de fragmentos culturales es asumida por los garífuna con el espíritu de su afirmación identitaria y de visibilización que debería darle beneficios. Pese a ello, los que ganan son los empresarios del turismo mientras los garífuna continúan siendo el eslabón débil de la cadena productiva y los menos beneficiados (Cuiset, 2009). Es la lógica de cruzar los imperativos económicos del Estado y los capitales nacionales y transnacionales que se han acoplado bien con el discurso multiculturalista de reconocimiento, pero que dejan por fuera las reivindicaciones de inclusión social y económica de los reconocidos.

Frente a una correlación de fuerzas desfavorable frente el Estado, los poderes económicos y los intereses a los que se enfrentan, la opción mayoritaria que sigue asumiendo el movimiento garífuna en sus diferentes expresiones es la de continuar afirmando sus identidades como mecanismo de lograr la inclusión social. 


\section{Referencias}

Agudelo, C. (2010). Génesis de redes transnacionales de movimientos afrolatinoamericanos. Su presencia en América Central. En O. Hoffmann (Ed.), Ciudadania y Politica entre los afrodescendientes en México y América central. México: CEMCA-INAH-IRD-UNAM.

Agudelo, C. (2012). Qu'est-ce qui vient après la reconnaissance? Multiculturalisme et populations noires en Amérique latine. En C. Gros y D. Dumoulin Kervran (Eds.), Le multiculturalisme au concret. Un modèle latino américain?. París, Francia: Presses Sorbonne Nouvelle.

Agudelo, C (2009). Comunicación: "El día nacional garífuna en Guatemala: de fiesta local a instrumentalización nacional/global" $53^{\circ}$ Congreso Internacional de Americanistas. Los pueblos americanos: cambios y continuidades. La construcción de lo propio en un mundo globalizado. Simposio: Expresiones culturales y dinámicas identitarias desde el Caribe contemporáneo. Ciudad de México, 19 al 24 de julio de 2009. Amaya, J. (2004). “'Reimaginando' la nación en Honduras: de la 'nación homogénea' a la 'nación pluriétnica'. Los negros garífunas de Cristales, Trujillo", Tesis doctoral en Estudios Latinoamericanos, Universidad Complutense de Madrid. Amaya, J. (2007). Las imágenes de los Negros Garifunas en la Literatura Hondureña y Extranjera. Tegucigalpa, Honduras: Cultura.

Anderson, M. (2007). When Afro Becomes (like) Indigenous: Garífuna and Afro-Indigenous Politics. The Journal of Latin American and Caribbean Anthropology, 12 (2), 384-413.

Anderson, M. (2008). Garinagu Hondureña y los significados de "Negro" en los 1930s y 1940s. Ponencia Congreso Diáspora, Nación y Diferencia, 10 al 13 de junio, Veracruz, México.

Anderson, M. y England, S. (2005). Auténtica cultura africana en Honduras? Los afrocentroamericanos desafían el mestizaje indohispano en Honduras. En D. Euraque et al. (Eds.), Memorias del Mestizaje. Cultura politica en Centroamérica de 1920 al presente (pp. 253-294). Guatemala: CIRMA.

Arrivillaga Cortés, A. (1985). Etnografía de la fiesta de San Isidro Labrador. Livingston, Izabal, Guatemala. La tradición popular, 54, 1-16. Arrivillaga, A. (2005). Marcos Sanchez Diaz from hero to hiuraha- two hundred years of Garífuna settlement in Central America. En J. Palacio, The Garifuna: A Nation across Borders. Essays in Social Antbropology (pp. 64-84). Belice: Cubola Press. 
Arrivillaga Cortés, A. (2006). Marcos Sánchez Díaz fundador y protector de gulfuiyumu. Guatemala: Comisión Presidencial contra la discriminación y el racismo.

Arrivillaga Cortés, A. (2009). La población garífuna migrante. Guatemala: CODISRA.

Beaucage, P. (1970). "Economic Anthropology of the Black Carib of Honduras", Tesis de doctorado, University of London.

Breton, R., Besada P., Bernabé J. (1665). Dictionnaire caraïbe - français. Paris, Francia: KARTHALA.

Burton, R. (1685). The English Empire in America. Londres, Inglaterra: Nathaniel Crouch.

Cáceres, R. (Ed). (2008). Tomo 1: Del olvido a la memoria: Africanos y afromestizos en la historia colonial de Centroamérica. San José: UNESCO.

Cayetano, M. y Cayetano, R. (2005). Garífuna language, dance, and music - a masterpiece of oral and intangible heritage of humanity. How did it happen?. En J. Palacio, The Garifuna: A Nation across Borders. Essays in Social Anthropology (pp. 230-249). Belice: Cubola Press. Cayetano, S. (1996). Garífuna History, Language and Cultura of Belize Central America and the Caribbean. Belice: Angelus Press.

Cohelo, R. (1995). Los Caribes Negros de Honduras. Tegucigalpa, Honduras: Guaymuras.

Conzemius, E. (1928). Ethnographic Notes on the Black Carib (Garif). American Anthropologist, 30, 183-205.

Cuisset O. (2009). Tourisme et Garifunas à Livingston, Guatemala. Economie et culture en contexte touristique. Documento de Trabajo No. 7. México: Proyecto AFRODESC. Disponible en: bttp:/ / mmm.ird.fr/afrodesc/IMG/pdf/Cuaderno7-Cuisset-3.pdf.

Davidson, W. (1974). The Caribs (Garífuna) of Central America. A map or their realm and Bibliography or research. Belizean Studies, 2 (4).

Davidson, W. (1979). Dispersal of the Garifuna in the Western Caribbean. Actes of the Forty-Second Internacional Congreso of Americanists, 6, 467-474.

Davidson, W. (1980). The Garífuna of Pearl Lagoon: Ethnohistory of an afro-american enclave in Nicaragua. Ethnobistory, 1 (27).

Du Tertre, J. B. (1671). Histoire Générale des Antilles habitées par les François $1635-$ 1671. París, Francia.

Euraque, D. (2004). Conversaciones históricas con el mestizaje y su identidad nacional en Honduras. Honduras: Centroeditorial. 
Euraque, D. et al. (Ed). (2005). Memorias del Mestizaje. Cultura política en Centroamérica de 1920 al presente. Guatemala: CIRMA.

Frühling, P., González, M. y Peter-Buvollen, H. (2007). Etnicidady nación. El desarrollo de la autonomía de la Costa Atlántica de Nicaragua. 1987-2007. Guatemala: F\&G Editores.

Gargallo, F. (2000). Los Garífuna de Centroamérica: reubicación, sobrevivencia y nacionalidad de un pueblo afroindoamericano. Políticay Cultura, 14, 89-107.

Gargallo, F. (2002). Garifuna Garinagu, Caribe. México: Siglo XXI.

González, N. (1976). From Black Carib to Garifuna: The coming of Age of an Ethnic Group, en Actes of the Forty-Second International Congress of Americanists, 6, pp. 577-588

González, N. (1988). Peregrinos del Caribe. Etnogénesis y etnohistoria de los garifunas. Tegucigalpa, Honduras: Editoria Guaymuras.

González, N. (1988a). Sojourners of the Caribbean: Ethnogenesis and Ethnohistory of the Garifuna. Estados Unidos: University of Illinois Press.

Gudmundson, L. (2009). Africanos y afrodescendientes en Centroamérica. Nuevo Mundo Mundos Nuevos, Debates. Disponible en http://nuevomundo. revues.org/index57996.html.

Gullick, C. (1976). Exiled from St. Vincent: The Development of Black Caribe Culture in Central America Up to 1945. Malta: Malta Progress Press.

Houdaille, J. (1954). Negros Franceses en América Central a fines del siglo XVIII. Antropología e Historia de Guatemala, 6 (1), 65-67.

Izard, G. (2003). La construcción política de la identidad garífuna en el Belice contemporáneo. Revista de las Américas. Historia y presente, (1).

Labat, J. (1970). The memoirs of Pere Labat, 1693-1705. Londres, Inglaterra: Frank Cass.

Labat, J. (1979). Voyage aux Iles de l'Amérique (Antilles), 1693-1705. París, Francia: Seghers.

Lizcano, F. (1993). La Población Negra en el Istmo Centroamericano. En L. M. Martínez Montiel (Coord.), Presencia Africana en Centroamérica. México: CONACULTA.

López García, V. (1994). La Babia de Puerto del Soly la Masacre de los Garifunas de San Juan. Tegucigalpa, Honduras: Guaymuras.

Meléndez, A. C. (1997). El enojo de las sonajas. Palabras del Ancestro. Tegucigalpa, Honduras: Graficentro. 
Mintz, S. y Price, R. (1992). The Birth of American Culture. An Anthropological Perspective. Boston, Estados Unidos: Bacon Press.

Mohr De Collado, M. (2007). Los garinagu en Centroamérica y otros lugares. Identidades de una población afro-caribe entre la tradición y la modernidad. INDIANA, 24.

ODECO, (2008). 211 años de presencia Garifuna en Centroamérica.

Palacio, J. (2005). Reconstructing Garífuna oral history - techniques and methods in the history of a Caribbean people. En J. Palacio, The Garifuna: A Nation across Borders. Essays in Social Anthropology (pp. 43-63). Belice: Cubola Press.

Palacio, J. (2005a). The multifaceted Garífuna: juggling cultural spaces in the 21 st century. En J. Palacio (Coord), The Garifuna a nation across borders. Essays in Social Anthropology (pp. 105-122). Belice: Cubola.

Rey, N. (2005). Quand la révolution, aux Amériques, était nègre... Caraïbes nöirs, negros franceses et autres « oubliés » de l'Histoire. París, Francia: Karthala.

Taylor, D. (1951). The Black Caribs of British Honduras. Viking Fund Publications in Anthropology, (17).

Taylor, D. (1958). Carib, Caliban, Cannibal. International Journal of American Linguistics, 24, 156-157.

Victoria, J. (s.f.). Los negros auxiliares de España en Centroamérica. Boletín AFEHC, (21). Recuperado el 4 de abril de 2006 de: http:/ / afehc-historiacentroamericana.org/375.

Wade, P. (2000). Raza y etnicidad en Latinoamérica. Quito, Ecuador: Abya-Yala. Young, W. (1975). An account of the Black Charaibs in the Island of St. Vincent. Londres, Inglaterra: Frank Cass. 
